\title{
The Role of Contact Tracing in the Management of SARS-cov 2 Infection in Childhood: a Retrospective Analysis
}

Giuseppe Gregori ( $\sim$ g.greg@agonet.it )

Primary Care Department Local Health Unit Piacenza https://orcid.org/0000-0003-2803-6518

Roberto Sacchetti

AZIENDA SANITARIA LOCALE PIACENZA

Michela Ridella

AZIENDA SANITARIA LOCALE PIACENZA

Elena Boselli

AZIENDA SANITARIA LOCALE PIACENZA

Ornella Righi

AZIENDA SANITARIA LOCALE PIACENZA

Goffreda Boiardi

AZIENDA SANITARIA LOCALE PIACENZA

Claudio Marenghi

AZIENDA SANITARIA LOCALE PIACENZA

Sonia Lenzini

AZIENDA SANITARIA LOCALE PIACENZA

Monica Cervi

AZIENDA SANITARIA LOCALE PIACENZA

Maria Pia Libè

AZIENDA SANITARIA LOCALE PIACENZA

Patrizia Armani

AZIENDA SANITARIA LOCALE PIACENZA

Monica Corna

AZIENDA SANITARIA LOCALE PIACENZA

Laura Zanolli

AZIENDA SANITARIA LOCALE PIACENZA

Valentina Allegri

AZIENDA SANITARIA LOCALE PIACENZA

Paola Balduzzi

AZIENDA SANITARIA LOCALE PIACENZA

Chiara Franzini 
AZIENDA SANITARIA LOCALE PIACENZA

\section{Federica Folli}

AZIENDA SANITARIA LOCALE PIACENZA

\section{Caterina Mura}

AZIENDA SANITARIA LOCALE PIACENZA

\section{Giovanni Demuru}

AZIENDA SANITARIA LOCALE PIACENZA

\section{Research Article}

Keywords: SARS-Cov 2, Contact tracing, Childhood

Posted Date: March 7th, 2022

DOI: https://doi.org/10.21203/rs.3.rs-1274042/v1

License: (c) (i) This work is licensed under a Creative Commons Attribution 4.0 International License. Read Full License 


\section{Abstract}

\section{Background}

Individuation and management of the contacts of confirmed COVID-19 infection cases allows to quickly identify and isolate any secondary cases and interrupt the chain of transmission of the infection. Contact tracing is unquestionably very useful in stemming the spread of the pandemic from SARS-Cov 2 however there are no pediatric data that have measured the effectiveness of this method.

\section{Methods}

From 30 October 2020 to 30 April 2021 ,during the second wave of the Covid pandemic, 19 primary care pediatricians reported suspected cases of SAR Cov 2 to the Public Health Service of the Piacenza district via a digital platform relating to a total pediatric population of about 17,500 children. All reported cases underwent a molecular PCR test as soon as possible and in any case within 48 hours. At the same time Public Hygiene Service implemented contact tracing in the same pediatric population in all children who were in close contact with positive cases .

\section{Results}

On the basis of clinical suspicion 1306 subjects underwent a molecular PCR nose pharyngeal swab for Covid $-19,107$ of them tested positive ( $8,2 \%$ of reports $-0.6 \%$ of the monitored population). In the same period, the Public Hygiene Service, through contact-tracing, identified another 1244 positive subjects in the same population of 17,500 children ( $7,1 \%$ of the monitored population).

\section{Conclusions}

Our experience confirm that contact tracing is strongly raccomended for the managment of the SAR Cov 2 pandemic . It was about eleven times more sensitive than the clinical criteria for identifying positive subjects in pediatric age, often asymptomatic, during the second wave of the Covid pandemic.

\section{Background}

SARS-Cov-2 infection symptoms are often similar to those of many other viral infections in childhood: the infection commonly proceeds in a paucisymptomatic or in a completely asymptomatic way $(1,2)$.

Starting from the first phase of the pandemic (February / March 2020), protective devices, spacing, contact tracing (CT ) were considered useful and necessary to reduce the spread of SARS-Cov-2 infection ; from the end of the year 2020 is available the vaccination against SARS-Cov-2 infection, now also for children over 5 years of age .

In Italy, the alert status for the presence of SARS-Cov-2 infection was officially declared on January 31, 2020 (3). On February 23, 2020, at the same time with the creation of the first "red zone" in Italy 
(Codogno), schools were also closed in the Piacenza district, which borders the "red zone" (4).

Italy began a full lockdown on March 8, 2020 (5).

Piacenza district recorded one of the highest cumulative mortality rates ( $>3$ deaths per thousand inhabitants) in Italy in the first phase of the pandemic(6).

Unfortunately, despite the Chinese experience, the speed of spread of the infection in our geographical area, the severity and number of cases have catch unprepared the Public Hygiene Services (PHS) in the first phase of the pandemic between February and May 2020.

Due to the low impact of the infection in pediatric age, most of the available resources were directed elsewhere: In this emergency situation, most children with suspected SARS-Cov-2 infection were not tested due to the lack of nasal swabs and mild symptoms, which rarely required hospitalization therefore it was not even possible to apply contact tracing due to lack of swabs, health personnel to perform swabs and to carry out tests in the laboratory.. In the first phase of the pandemic, primary care pediatricians (PCP) could report suspected cases to the PHS to carry out the molecular swab if epidemiological (close contact with a positive subject or from a red zone) and clinical (7) criteria were present simultaneously. However, in a series of 175 suspected cases reported at that time by 13 PCP (unpublished data) only 46 underwent molecular swabs almost always many days after reporting and only 2 were positive The symptoms prevalent in this series (mean age 6 years) were fever, cough, gastroenterological disturbances, headache, dermatological manifestations.

For epidemiological purpose, one month after the end of lockdown (June 2020), National Health Service underwent to sierological test of Covid-19 antibodies (CMIA Abbott) about half of these children : $50 \%$ of them had significant IgG anti-Covid-19 levels. From this survay, which also involved the adult population, it was estimated that the number of subjects affected by SARS-Cov-2 infection in the first wave was 6 times higher than that diagnosed by nose-pharingeal molecolar test (8).

From May 2020, the presence of clinical criteria was considered sufficient to report a suspected case of SARS-Cov-2 infection to the PHS. (9) .Reopening of school activities in September 2020 and before the beginning of a second pandemic wave (which then occurred from October 2020) the PHS has scheduled the execution of the CT whenever there is a positive case with the aim to stem the effects of the spread of the virus. The purpose of this work is to quantify how effective the CT activity is in identifying SARS-Cov2 positive pediatric subjects compared to the only reporting of suspected cases based of clinical elements. This type of survey was possible because the Italian National Health Service provides that children up to the age of 14 are followed by PCP and in our area about $96 \%$ of children benefit from this type of assistance.

\section{Materials And Methods}


From October 30, 2020, PCPs reported children with suspected symptoms of SARS-Cov-2 infection to the PHS through a digital platform to undergo a nasopharyngeal molecular swab. The swab was carried out within 48 hours of reporting. The PHS also carried out the CT of all the children who had been in close contact with a positive case at school, in the family or in another settings. All cases were included in a database in which each PCP was able to identify their patients who tested positive on the basis of clinical suspicion or through CT.

Clinical suspects were those reported in the national and international literature (10) while the CT was performed whenever an ascertained case had had close contact * with other people.

${ }^{*}$ close contact is

- a person who lives in the same home as a COVID-19 case;

- a person who has had direct physical contact with a COVID-19 case (for example a handshake);

- a person who has had unprotected direct contact with the secretions of a COVID19 case (for example, touching used paper handkerchiefs with bare hands);

- a person who has had direct contact (face to face) with a COVID-19 case, at a distance of less than 2 meters and at least 15 minutes;

- a person who has been in a closed environment with a COVID-19 case in the absence of suitable PPE;

- a person who has traveled seated by train, plane or any other means of transport within two seats in any direction relative to a COVID-19 case; the travel companions and the staff assigned to the section of the plane / train where the index case was sitting are also close contacts.

\section{Results}

In the period October 2020 - April 2021, 19 pdfs following a total of 17500 children aged 0-14 years reported 1306 symptomatic patients to undergo a nasopharyngeal molecular swab for suspected SARSCov-2 infection.

107 (8.2\% of reports $-0.6 \%$ of the monitored population) tested positive for the molecular swab for Covid-19. In the same period, the PHS, through the CT, identified another 1244 positive subjects in the same population (7.1\% of the monitored population). The CT activity is at least 11 times more effective in identifying coronavirus infected subjects

\section{Discussion}

The measures to stem the spread of the pandemic that have proved to be fundamental include the correct diagnosis (execution of the swab in suspected cases) the isolation of positive cases, the quarantine of close contacts and preventive measures (use of protective devices, spacing and CT or 
identification of asymptomatic cases). Since December 2020, a new opportunity has been added: vaccination against Covid 19.

There is much debate about the reasons that determine the presence of asymptomatic cases and why children often belong to this group. (1)

Some of the patients identified through the CT subsequently became symptomatic, manifesting fever, cough, sore throat, headache, gastrointestinal disorders and probably some of them would have been subjected anyway to tests for coronavirus in a short time. The purpose of our analysis was, however, to answer the question: is it possible to understand and quantify how much CT helps us to intercept subjects infected with coronavirus, especially in childhood where paucisymptomatic or asymptomatic cases are the majority?

Much has also been insisted on the importance of CT as a measure to limit the spread of the pandemic (11) although this measure alone appears insufficient to limit the spread of the infection(12)

In this work a population of 17,500 children was monitored from the clinical point of view by the family pediatricians and from the preventive point of view through the CT performed by the PHS whenever one of these children had close contact with a positive subject.

For a real health prevention strategy, the $\mathrm{CT}$ is essential and necessary to limit the spread of infection during a pandemic. The effectiveness and efficacy of CT seem to be certainly high while we can't evaluate the efficiency because it was not possible to know how many nose-pharingeal molecolar test were performed.

The effectiveness was at least eleven times higher than that of the clinical evaluation of suspected cases based on clinical data alone. Our data were detected when alpha variant of SARS COV 2 infection was prevalent in the European continent and in Italy(13): probably the effectiveness and efficacy of CT could be different based on the degree of contagiousness RO and RT of other SARS COV 2 variants such as delta and omicron.

In an endemic situation, it is not excluded that other strategies to contain the spread of the virus, such as the use of molecular salivary swabs, could be more appropriate. In any case at present our opinion is: CT, impossible to do without it.

\section{Conclusions}

Detection of SARS-Cov-2 infection based on clinical data alone is very ineffective. Unquestionably the CT activity appears essential for the managment of the COVID 19 pandemic and it was about eleven times more effective than the clinical criteria for identifying positive subjects in childhood during the second wave of the Covid pandemic. 


\section{Abbreviations}

$\mathrm{CT}=$ Contact Tracing, $\mathrm{PHS}=$ Public Hygiene Services, $\mathrm{PCP}=$ Primary Care Pediatrician

\section{Declarations}

\section{Ethics approval and consent to participate:}

Not applicable: On October 13, 2021 the CE AVEN Ethics Committee declared on the basis of the regulation Art.3 available at https://www.aou.mo.it/ComitatoEticoAVEN that the data collection promoted by the health professionals working in this belonging structure does not fall within the competence of the $\mathrm{CE}$, in the absence of external Sponsors.

\section{Consent for publication:}

not applicable

\section{Availability of data and material:}

The datasets used and/or analysed during the current study are available from the corresponding author on reasonable request.

\section{Competing interests:}

The authors declare that they have no competing interests

\section{Funding:}

The authors did not receive any funding for the research

\section{Authors' contributions:}

GG e RS conceptualized and designed the survey, $\mathrm{EB}, \mathrm{OR}, \mathrm{GB}, \mathrm{CM}, \mathrm{SL}, \mathrm{MC}, \mathrm{MPL}, \mathrm{PA}, \mathrm{MC}, \mathrm{LZ}, \mathrm{MR}, \mathrm{VA}, \mathrm{PB}, \mathrm{CF}, \mathrm{FF}, \mathrm{GG}, \mathrm{CM}, \mathrm{GD}, \mathrm{RS}$ collected the data,

GG analysed the data, GG and RS wrote the manuscript ,MR reviewed the manuscript . All authors approved the final manuscript as submitted and agreed to be accountable for all aspects of the work.

\section{Acknowledgements:}

We would like to thank Anna Maria Andena MD for her technical support

\section{References}


1. Zimmermann P, Curtis N Coronavirus Infections in Children Including COVID-19. An Overview of the Epidemiology, Clinical Features, Diagnosis, Treatment and Prevention Options in Children. Pediatric Infect Dis J. 2020; 39(5):355-368.

2. Garazzino S, Montagnani C, Donà D, Meini A ,Felici E, Vergine G et al. Multicentre Italian study of SARS-CoV-2 infection in children and adolescents, preliminary data as at 10 April 2020. Euro Surveill. $2020 ; 25(18)$.

3. Gazzetta Ufficiale della Repubblica Italiana :delibera del Consiglio dei Ministri 31 gennaio 2020 https://www.gazzettaufficiale.it/eli/id/2020/02/01/20A00737/sg Accessed 1 February 2020

4. Misure urgenti in materia di contenimento e gestione dell'emergenza epidemiologica da COVID-19. Gazzetta Ufficiale della Repubblica Italiana . Decreto legge 23 febbraio 2020 https://www.gazzettaufficiale.it/eli/id/2020/02/23/20G00020/sg Accessed 23 February 2020

5. Disposizioni urgenti per il potenziamento del Servizio sanitario nazionale in relazione all'emergenza COVID-19. Decreto Legge 9 Marzo 2020 Gazzetta ufficiale della Repubblica Italiana https://www.gazzettaufficiale.it/eli/id/2020/03/09/20G00030/sg Accessed 9 March 2020

6. Rapporto sulla mortalità della popolazione residente a cura di ISS e ISTAT https://www.istat.it/it/archivio/242149 Accessed 22 September 2021

7. Coronavirus: nuove indicazioni e chiarimenti del Ministero della Salute https://www.unipi.it/index.php/news/item/17600-coronavirus-nuove-indicazioni-e-chiarimenti-delministero-della-salute Accessed 24 February 2020

8. Indagine sierologica su Covid-19 condotta da Ministero della Salute e Istat, https://www.istat.it/it/archivio/242676 Accessed 22 September 2021

9. Ministero della Salute: Ricerca e gestione dei contatti di casi COVID-19 (Contact tracing)) https://www.apiverona.it/wp-content/uploads/2020/10/contatto-stretto-290520-n-18584-circministero-salute-.pdf Accessed 29 May 2020

10. Filia A., Urdiales AM, Rota MC Guida per la ricerca e gestione dei contatti (contact tracing) dei casi di COVID-19. Versione del 25 giugno 2020.2020, ii, 41 p. Rapporto ISS COVID-19 n. 53/2020

11. Gruppo di lavoro ISS Bioetica COVID-19 Supporto digitale al tracciamento dei contatti (contact tracing) in pandemia: considerazioni di etica e di governance. Versione del 17 settembre 2020. 2020, iii, 25 p. Rapporto ISS COVID-19 n. 59/2020

12. Shakiba M, Nazemipour M, Heidarzadeh A et al. Prevalence of asymptomatic COVID-19 infection using a seroepidemiological survey Epidemiol Infect.. 2020 Nov 13;148:e300. doi: $10.1017 /$ S0950268820002745.

13. Istituto Superiore di Sanità Comunicato Stampa n 14/2021 https://www.iss.it/coronavirus/-/asset_publisher/1SRKHcCJJQ7E/content/id/5647546 Accessed 5 March 2021 